\title{
Cost-effectiveness of physical activity in the management of COPD patients in the UK
}

This article was published in the following Dove Press journal: International Journal of COPD

\author{
Mafalda Ramos' \\ Mark Lamotte' \\ Laetitia Gerlier' \\ Per Svangren ${ }^{2}$ \\ Anna Miquel-Cases ${ }^{3}$ \\ John Haughney ${ }^{4}$ \\ 'Real World Evidence Solutions, \\ IQVIA, I 930 Zaventem, Belgium; \\ ${ }^{2}$ Core Respiratory, Global Product \\ and Portfolio Strategy - Global Payer \\ Evidence and Pricing, AstraZeneca \\ Gothenburg R\&D, SE-43I 83 \\ Mölndal, Sweden; ${ }^{3}$ Global Price \\ and Reimbursement, Global Payer \\ Evidence and Pricing, AstraZeneca \\ Gothenburg R\&D, Cambridge CB2 \\ 8PA, UK; ${ }^{4}$ Academic Primary Care \\ Division of Applied Health Sciences, \\ University of Aberdeen, Aberdeen \\ AB25 2ZD, UK
}

Background: While the Global Initiative for Chronic Obstructive Lung Disease (GOLD) guidelines advise exercise to reduce disease progression, little investment in promoting physical activity (PA) is made by health care authorities. The purpose of this study was to estimate the cost-effectiveness of regular PA vs sedentary lifestyle in people with COPD in the UK.

Methods: Efficacy, quality of life, and economic evidence on the PA effects in COPD patients were retrieved from literature to serve as input for a Markov microsimulation model comparing a COPD population performing PA vs a COPD population with sedentary lifestyle. The GOLD classification defined the model health states. For the base case, the cost of PA was estimated at zero, a lifetime horizon was used, and costs and effects were discounted at 3.5\%. Analyses were performed from the UK National Health Service (NHS) perspective. Uncertainty around inputs and assumptions were explored via scenario and sensitivity analyses, including a cost threshold analysis. Outcomes were cost/quality-adjusted life year (QALY) gained and cost/year gained. Results: Based on our model, the effects of PA in the UK COPD population would be lower mortality $(-6 \%)$, fewer hospitalizations $(-2 \%)$, gains in years $(+0.82)$ and QALYs $(+0.66)$, and total cost savings of $£ 2,568$. The cost/QALY and cost/year gained were dominant. PA was costsaving at costs $<£ 35 /$ month and cost-effective at cost $<£ 202 /$ month. The main model drivers were age and PA impact on death and hospital-treated exacerbations.

Conclusion: Including PA in the management of COPD leads to long-term clinical benefits. If the NHS promotes only exercise via medical advice, this would lead to health care cost savings. If the NHS chose to fund PA, it would still likely be cost-effective.

Keywords: cost-effectiveness, physical activity, exercise, COPD, microsimulation, Markov

\section{Introduction}

COPD represents a serious health issue, a major cause of morbidity and mortality. ${ }^{1}$ Globally, 3.17 million deaths were caused by the disease in $2015 .^{2}$ The primary cause of COPD is not only exposure to tobacco smoke but also exposure to indoor and outdoor air pollution and occupational dusts and fumes. ${ }^{2}$

COPD is a progressive life-threatening lung disease that causes breathlessness, an uncomfortable and disturbing symptom. As a result, patients may avoid activities that make them feel breathless, and by doing so become further deconditioned, making future exercise more difficult, which leads to a cycle of decline. This promotes sedentary behavior, diminishes quality of life (QOL), and results in poorer COPD outcomes and a faster progression of the disease, thereby increasing the risk of death. ${ }^{3}$

Figures from the British Lung Foundation estimate that in 2012, 2\% of the total population lived with COPD (1,274,100 individuals), making it the most common lung disease in the UK after asthma. It is responsible for $1.7 \%$ of all hospital admissions and bed days. ${ }^{4}$
Correspondence: Mafalda Ramos RWES, IQVIA, Corporate Village, Davos Building Da Vincilaan 7 , 1930 Zaventem, Belgium Email mafalda.ramos@iqvia.com 
Global Initiative for Chronic Obstructive Lung Disease (GOLD) guidelines ${ }^{1}$ indicate that the benefits of pulmonary rehabilitation (PR) in COPD patients are considerable. PR improves symptoms, QOL, and physical and emotional participation in everyday activities. Two pillars of PR, smoking cessation and exercise, are highly advised to promote the reduction of disease progression, by diminishing the intensity of lung function decline.

From the health care authorities' perspective, promoting exercise or any intervention that slows down the progression of COPD is defined as a health policy priority. Nonetheless, as exercise is seen more as a lifestyle change rather than a health care intervention, there has been little investment in promoting exercise in COPD patients to date.

The aim of the current study was to collect the necessary evidence to support the hypothesis that exercise/physical activity (PA) improves COPD outcomes and QOL. These data subsequently serve as inputs for a cost-effectiveness analysis (CEA) which aimed to demonstrate the long-term clinical and economic value of regular exercise in a COPD population compared with a COPD population with a sedentary lifestyle.

\section{Methodology}

This study was divided into two parts, a targeted literature review (TLR) and a CEA.

A TLR was conducted to identify, collect, and summarize relevant evidence on the effects of PA in COPD patients. This analysis identified studies reporting different forms of exercise in COPD patients: PA, Tai Chi, and PR. The extracted evidence reported efficacy, QOL, and economic outcomes. Challenges and limitations with the different metrics and methods used to measure exercise were reported. Details of the methodology and results of the TLR can be found in the Supplementary material.

Among the several studies identified by the TLR, GarciaAymerich et al ${ }^{5,6}$ provided most information on the efficacy of PA (the impact of PA on the decline in $\mathrm{FEV}_{1}$, on the risk of exacerbations and death). For this reason both were selected as the base for this CEA. ${ }^{5,6} \mathrm{PA}$ was defined as the combination of the three PA levels (low, moderate, and high) as reported by Garcia-Aymerich et al. ${ }^{5,6}$ Sedentary life is represented by "very low PA" (Table 1).

\section{Model structure}

The majority of COPD CE models are cohort-based Markov simulation models. ${ }^{7}$ However, recently COPD disease statistical models demonstrated the interdependence between predictors and outcomes of the disease. ${ }^{8-12}$ As Markov models are "memoryless," they are limited in their ability to deal simultaneously and accurately with the complex dependencies between patient risk factors, clinical events, and intervention benefits. To overcome this complexity, a combined Markov microsimulation model was constructed in MS Excel to predict the CE of PA.

Using a microsimulation model, individual patients are simulated over time. Trackers were incorporated into the model engine to record health states, COPD events, smoking status, and PR program over time. The model also explored how each factor influenced the $\mathrm{FEV}_{1}$ progression and vice versa.

Patient characteristics were defined by age, gender, smoking status, and initial lung function capacity according to COPD severity level. Patient lung function progression and movement between health states was traced over time, by tracking the association between $\mathrm{FEV}_{1}$ value and GOLD criteria for severity levels. The model has five health states (Figure 1). Aside from the "Death" health state, the other four health states represent COPD disease severity using the GOLD 2017 classification for airflow obstruction: GOLD stage I or "mild" ( $\mathrm{FEV}_{1}$ predicted value $\geq 80 \%$ ), GOLD stage II or "moderate" (FEV ${ }_{1}$ predicted value $\geq 50 \%$ and $<80 \%$ ), GOLD stage III or "severe" $\left(\mathrm{FEV}_{1}\right.$ predicted value $\geq 30 \%$ and $<50 \%$ ), and GOLD stage IV or "very severe" $\left(\mathrm{FEV}_{1}\right.$ predicted value $\left.<30 \%\right){ }^{1}$

Within any health state, a patient can suffer COPD events or can die from other causes. The COPD events are mild/ moderate or severe exacerbations. After death, patients move

Table I The reported levels of PA that are used to define the intervention PA

\begin{tabular}{l|l|l|l}
\hline $\begin{array}{l}\text { Levels } \\
\text { of PA }\end{array}$ & Time & Description & $\begin{array}{l}\text { Metabolic equivalent } \\
\text { unit levels }\end{array}$ \\
\hline Low & $<2$ hours/week & Reading, watching television or movies, or engaging in light PA (as walking or biking) & $<4$ \\
Moderate & $\begin{array}{l}2-4 \text { hours/week } \\
\text { Engaging in light physical activity (as walking or biking) } \\
\text { High }\end{array}$ & $\begin{array}{l}\text { Engaging in light physical activity (as walking or biking) for }>4 \text { hours/week or in more } \\
\text { vigorous activity for any frequency }\end{array}$ & \begin{tabular}{l}
$>6$ \\
\hline
\end{tabular}
\end{tabular}

Note: Data from Garcia-Aymerich et al. ${ }^{5,6}$

Abbreviation: PA, Physical activity. 


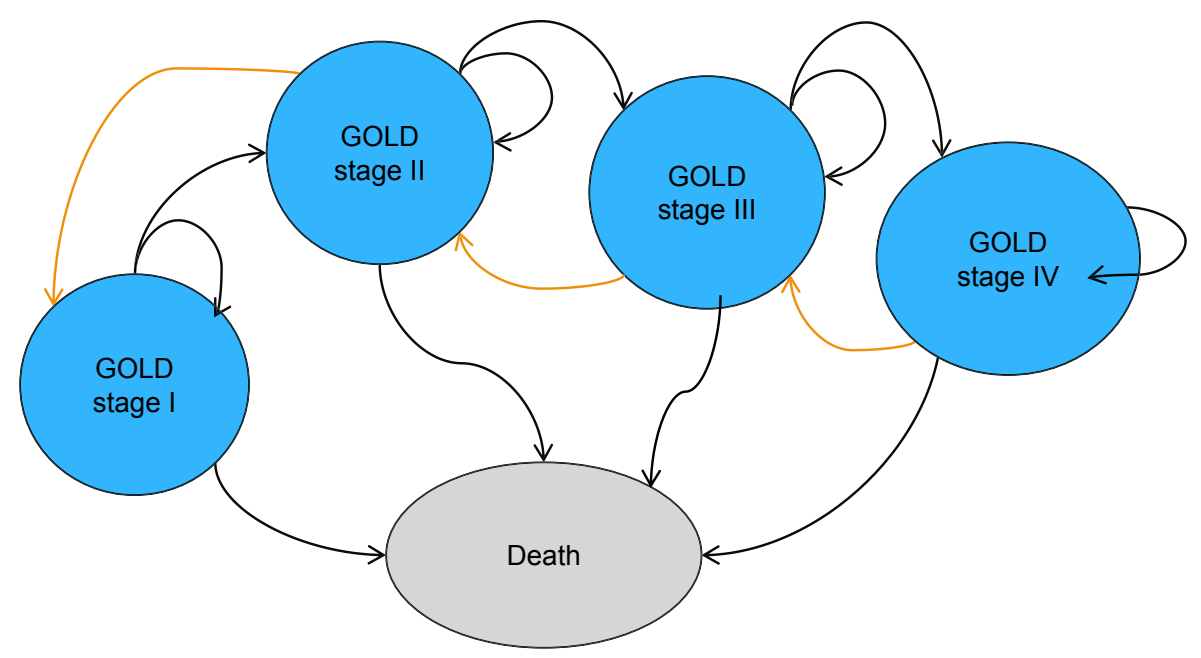

Figure I Five health-state model structure.

Notes: Patients can enter the model in the GOLD stage I, II, III, or IV health states. Orange arrows represent the possibility for a patient to move to a less severe health state due to the improvement of FEV . Black arrows represent the natural progression of the disease or a slowdown of progression obtained by practicing physical activity, which results in faster or slower movement of patients to a more severe health state. In each health state, there is also a possibility to die.

Abbreviation: GOLD, Global Initiative for Chronic Obstructive Lung Disease.

to the absorbing health state "Death." The progression of COPD is dependent on the decline in $\mathrm{FEV}_{1}$, thereby patient transitions between health states are dictated by the $\mathrm{FEV}_{1}$ values. The risk of exacerbation, utility value, resource use, and cost attribution are dependent on the severity level/health state that the patient encounters.

The clinical benefit of PA is represented by a reduced $\mathrm{FEV}_{1}$ decline, a lower risk of hospitalizations due to exacerbations and a lower risk of dying. Being a current smoker has a heavier impact on the decline in $\mathrm{FEV}_{1}$ and on the exacerbation rate. Furthermore, after a severe exacerbation, the patient might attend a PR program and, as a result, might stop smoking.

The model has a lifelong time horizon (35 years) and monthly cycles. For each deterministic analysis, the microsimulation simulated 5,000 distinct patients.

\section{Clinical data}

As this study targets the UK COPD population, patients were simulated stochastically using the baseline characteristics described in a large UK primary care database on patients with $\mathrm{COPD}^{13}$ and using national height statistics. ${ }^{14}$ In total, the study comprised 9,219 COPD patients classified according to the GOLD classification for airflow limitation (Table 2).

\section{FEV, values}

\section{Model entry}

Upon entry to the model, patients are represented by their initial lung function capacity, measured in terms of $\mathrm{FEV}_{1}$. To estimate the initial $\mathrm{FEV}_{1}$ values, age-gender-heightdependent predicative equations were used. ${ }^{15}$ In the current study, UK-specific equations published by British Thoracic

Table 2 Patient baseline characteristics

\begin{tabular}{|c|c|c|c|c|c|c|c|}
\hline & \multirow{2}{*}{$\begin{array}{l}\text { Deterministic } \\
\text { Mean }\end{array}$} & \multicolumn{2}{|l|}{ OWSA } & \multicolumn{4}{|l|}{ Microsimulation } \\
\hline & & Lower & Upper & Units & Distribution & Alpha & Beta \\
\hline Proportion of males & $51 \%$ & $41 \%$ & $61 \%$ & 0: female; I: male & Binomial $^{\mathrm{a}}$ & $100 \%$ & $51 \%$ \\
\hline Height male ${ }^{14}$ & 175 & 149 & 201 & $\mathrm{~cm}$ & Normal $^{b}$ & 175 & 18 \\
\hline Height female ${ }^{14}$ & 162 & 138 & 186 & $\mathrm{~cm}$ & Normal ${ }^{\mathrm{b}}$ & 162 & 17 \\
\hline Age & 70 & 59 & 80 & Years & Normal ${ }^{b}$ & 52 & 12 \\
\hline Proportion of smokers & $37 \%$ & $30 \%$ & $45 \%$ & 0: non-smoking; I: smoking & Binomial $^{a}$ & $100 \%$ & $37 \%$ \\
\hline GOLD stage I & $17.50 \%$ & $14.00 \%$ & $21.00 \%$ & $0:$ no; I: yes & Dirichlet & & \\
\hline GOLD stage II & $52.00 \%$ & $61.60 \%$ & $42.40 \%$ & $0:$ no; I: yes & Dirichlet & & \\
\hline GOLD stage III & $25.30 \%$ & $20.20 \%$ & $30.40 \%$ & 0: no; I: yes & Dirichlet & & \\
\hline GOLD stage IV & $5.20 \%$ & $4.20 \%$ & $6.20 \%$ & 0: no; I: yes & Dirichlet & & \\
\hline
\end{tabular}

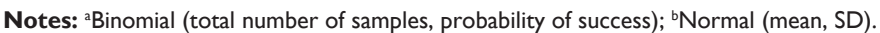

Abbreviations: GOLD, Global Initiative for Chronic Obstructive Lung Disease; OWSA, one-way sensitivity analysis. 
Society COPD consortium were used. ${ }^{16}$ These equations predict the lung function of males and females in the UK, according to age (in years) and height (in m).

$$
\begin{aligned}
& \mathrm{FEV}_{1 \text { females }}^{\text {healthy individual }}=3.95 * \text { Height }-0.025 * \text { Age }-2.60 \\
& \mathrm{FEV}_{1 \text { hales }}^{\text {healthy individual }}=4.30 * \text { Height }-0.029 * \text { Age }-2.49
\end{aligned}
$$

A multiplication factor was used to derive the mean $\mathrm{FEV}_{1}$ value specific of each health state (health state i) out of the initial lung function of a healthy individual. ${ }^{15}$ This factor was defined as the midpoint between the extreme $\mathrm{FEV}_{1}$ predicted values of the GOLD criteria.

$$
\begin{aligned}
& \mathrm{FEV}_{\text {lfemales }}^{\text {health state } i} \\
& =\mathrm{FEV}_{\text {lfeamales }}^{\text {healthy individual }} * \text { Multiplication factor }^{\text {health state } i} \\
& \mathrm{FEV}_{1 \text { males }}^{\text {health state } i} \\
& =\mathrm{FEV}_{1 \text { hales }}^{\text {healthy individual } * \text { Multiplication factor }} \text { health state } i^{\text {hen }}
\end{aligned}
$$

\section{Progression of the disease}

The natural course of the disease causes the lung function to decrease faster over time compared to healthy individuals.
The speed of the decline depends on the occurrence of exacerbations, smoking behavior, and interventions like PA and PR.

The relationship between exacerbations and $\mathrm{FEV}_{1}$ decline by GOLD stage was reported by Dransfield et al. ${ }^{17}$ In the sedentary arm, the $\mathrm{FEV}_{1}$ decline per type of exacerbation described by these authors was applied to reflect patient lung function deterioration each time an exacerbation occurred (Table 3 ). As the model runs on monthly cycles, the reported annual $\mathrm{FEV}_{1}$ data were converted to monthly data, by dividing by 12 . In the sedentary arm and in the absence of exacerbation, the monthly $\mathrm{FEV}_{1}$ decline was 2.08, 1.58, 0.67 , and $0.33 \mathrm{~mL}$ in GOLD stage I, II, III, and IV, respectively (Table 3).

Following a severe exacerbation, the greatest FEV decline was found in GOLD stage I, with an additional $88 \mathrm{~mL} /$ event decline after stabilization of the patient. ${ }^{17}$ Statistically significant but smaller effects were observed in both GOLD stage II and III subjects (22 mL) (Table 3). The effect of moderate exacerbations on $\mathrm{FEV}_{1}$ decline was not

\begin{tabular}{|c|c|c|c|c|c|}
\hline \multicolumn{2}{|l|}{ FEV , effect due to an exacerbation in $\mathrm{mL}^{17}$} & $\begin{array}{l}\text { Annual FEV, } \\
\text { decline (without } \\
\text { exacerbation) }\end{array}$ & $\begin{array}{l}\text { Monthly FEV, } \\
\text { decline (without } \\
\text { exacerbation) }\end{array}$ & $\begin{array}{l}\text { With mild/ } \\
\text { moderate } \\
\text { exacerbation } \\
\text { (as add on)* }\end{array}$ & $\begin{array}{l}\text { With severe } \\
\text { exacerbation } \\
\text { (as add on)* }\end{array}$ \\
\hline \multicolumn{2}{|l|}{ GOLD stage I } & 25.0 & 2.08 & 0.0 & 88.0 \\
\hline \multicolumn{2}{|l|}{ GOLD stage II } & 19.0 & 1.58 & 0.0 & 22.0 \\
\hline \multicolumn{2}{|l|}{ GOLD stage III } & 8.0 & 0.67 & 0.0 & 22.0 \\
\hline \multicolumn{2}{|l|}{ GOLD stage IV } & 4.0 & 0.33 & 0.0 & 0.0 \\
\hline Annual FEV, decline mL/year & $\mathbf{N}$ & Mean & $95 \% \mathrm{Cl}$ & \multicolumn{2}{|c|}{ Decline per PA level } \\
\hline Low PA (=sedentary lifestyle) & 1,035 & 17.9 & (Reference) & \multicolumn{2}{|c|}{17.9} \\
\hline FEV, change compared to low PA & & \multicolumn{2}{|l|}{ As add on } & & \\
\hline $\begin{array}{l}\text { Moderate PA } \\
\text { High PA } \\
\text { PA (combined low, moderate, and high PA) }\end{array}$ & $\begin{array}{l}2,418 \\
3,166\end{array}$ & $\begin{array}{l}-1.6 \\
-3\end{array}$ & $\begin{array}{l}(-1.1 ; 4.3) \\
(0.4 ; 5.6)\end{array}$ & \multicolumn{2}{|l|}{$\begin{array}{l}16.3 \\
14.9 \\
16.37\end{array}$} \\
\hline $\begin{array}{l}\text { FEV } \text { increments by level of PA and } \\
\text { GOLD stage }\end{array}$ & All patients & GOLD stage I & GOLD stage II & GOLD stage III & GOLD stage IV \\
\hline $\begin{array}{l}\text { FEV } \text {, decline in sedentary arm, } \mathrm{mL} / \text { year } \\
\mathrm{FEV} \text {, ratio by GOLD stage } \\
\mathrm{FEV} \text {, benefit in the PA arm }\end{array}$ & & $\begin{array}{l}25 \\
1\end{array}$ & $\begin{array}{l}19 \\
0.76\end{array}$ & $\begin{array}{l}8 \\
0.32\end{array}$ & $\begin{array}{l}4 \\
0.16\end{array}$ \\
\hline Per year & 16.37 & 8.63 & 6.56 & 2.76 & 1.38 \\
\hline Per month & 1.36 & 0.72 & 0.55 & 0.23 & 0.12 \\
\hline
\end{tabular}
statistically significant and as such not included in the model. Also, the effect of severe exacerbations on $\mathrm{FEV}_{1}$ decline in patients in GOLD stage IV was not statistically significant; therefore, its impact was assumed to be null. In the case of

Table $3 \mathrm{FEV}$, decline per health state, per exacerbation, and PA level

Notes: *Assumed as acute events; therefore, its full effect is applied when the event occurs.

Abbreviations: GOLD, Global Initiative for Chronic Obstructive Lung Disease; N, total number of patients per PA level; PA, physical activity. 
severe exacerbation, the full effect on $\mathrm{FEV}_{1}$ decline was applied in the cycle in which the event occurred (Table 3).

To estimate $\mathrm{FEV}_{1}$ decline in the PA arm, the impact of low, moderate, and high PA on $\mathrm{FEV}_{1}$ decline published by Garcia-Aymerich et $\mathrm{al}^{5}$ was considered. The overall effect of PA, in the PA arm, was defined as the average effect of the three levels of PA (16.37 mL/year). ${ }^{5}$ Unfortunately, this study is not COPD specific and only $11 \%$ of patients had COPD. For this reason, we assumed that the demonstrated benefit of $P A$ in reducing the $F E V_{1}$ decline is valid for COPD patients in GOLD stage I. For the remaining GOLD stages, to quantify the annual $\mathrm{FEV}_{1}$ effect of PA, the following methodology was applied. First, to estimate the $\mathrm{FEV}_{1}$ decline in the PA arm and GOLD stage $\mathrm{I}$, the $\mathrm{FEV}_{1}$ decline in the sedentary arm and that in the PA arm were subtracted $(25.00-16.37=8.63 \mathrm{~mL})$

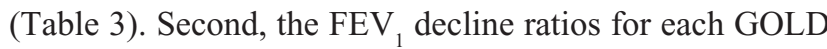
stage were estimated for the sedentary arm by dividing the total $\mathrm{FEV}_{1}$ effect of GOLD stage II, III, and IV in the sedentary arm with the total effect in GOLD stage I in the sedentary arm $(0.76,0.32$, and 0.16$)$ (Table 3$)$. Third, to estimate the PA benefit in GOLD stage II, III, and IV, each FEV decline $_{1}$ in the sedentary arm was subtracted by the product of $\mathrm{FEV}_{1}$ decline of $\mathrm{PA}$ and the $\mathrm{FEV}_{1}$ decline ratio in the GOLD stage of interest $(6.56,2.76$, and $1.38 \mathrm{~mL}$ ) (Table 3).

The total $\mathrm{FEV}_{1}$ effect per patient by smoking status was determined by multiplying the total $\mathrm{FEV}_{1}$ decline with a specific $\mathrm{FEV}_{1}$ smoking ratio. In the case of an ex-smoker, we assumed the effect to be equal to non-smoker patients $\left(\mathrm{FEV}_{1}\right.$ ratio $\left.=1\right)$. In smokers, $\mathrm{FEV}_{1}$ decline is 1.57 times higher than that in non-smokers. This figure was obtained as the ratio between the $\mathrm{FEV}_{1}$ decline of heavy smokers and non-smokers reported by Fletcher and Peto $(66 / 42 \mathrm{~mL}) .^{18}$

$\mathrm{PR}$ reduces the impact of severe exacerbations on $\mathrm{FEV}_{1}$ decline. ${ }^{19-21}$ Elkhateeb et $\mathrm{al}^{21}$ showed that by comparing the spirometric data in 45 COPD patients after 6- 8 weeks, equally divided between an aerobic training group, a respiratory training group, and a control group, the respiratory training group had a benefit of $8.8 \pm 3.5 \mathrm{~mL}$, compared to the control group. This benefit was assigned to the patients after initiating PR.

Finally, there is a minimum $\mathrm{FEV}_{1}$ needed to be compatible with life. To represent this threshold when simulating patient's progression and survival, it was assumed that patients die when they cross this $\mathrm{FEV}_{1}$ threshold. This minimum $\mathrm{FEV}_{1}$ of $10 \%$ of the patient lung function capacity was derived from Fletcher and Peto. ${ }^{18}$

\section{Events}

\section{Exacerbations}

Exacerbations are divided into mild/moderate and severe exacerbations (requiring a hospitalization). The risk of mild/ moderate exacerbations varies by GOLD stage only. The risk of severe exacerbations varies by GOLD stage and also intervention, as demonstrated by Garcia-Aymerich et al (Table 4). ${ }^{6}$

The monthly risk of all types of exacerbations and the proportion of severe exacerbations treated in hospital by GOLD stage were taken from a previously published health economic model. ${ }^{22}$ Based on this, the monthly risk of severe exacerbations per GOLD stage was calculated. After subtracting "the risk of severe exacerbations" from the "the risk of all exacerbations," the monthly risk of mild/moderate

Table 4 Exacerbation per GOLD stage and PA level

\begin{tabular}{|c|c|c|c|c|c|}
\hline & & \multicolumn{4}{|c|}{ Risk of exacerbations per GOLD stage ${ }^{22}$} \\
\hline & & \multirow{2}{*}{$\begin{array}{l}\text { Proportion of severe } \\
\text { exacerbations }\end{array}$} & \multicolumn{3}{|c|}{ Monthly risk (\%) } \\
\hline & & & $\begin{array}{l}\text { Any type of } \\
\text { exacerbation }\end{array}$ & $\begin{array}{l}\text { Severe } \\
\text { exacerbation }\end{array}$ & $\begin{array}{l}\text { Moderate } \\
\text { exacerbation }\end{array}$ \\
\hline GOLD stage I & & 0.684 & 19 & 13 & 6 \\
\hline GOLD stage II & & 0.684 & 19 & 13 & 6 \\
\hline GOLD stage III & & 0.625 & 24 & 15 & 9 \\
\hline GOLD stage IV & & 0.667 & 30 & 20 & 10 \\
\hline \multicolumn{6}{|c|}{ Adjusted associations between PA level and COPD admissions due to a severe exacerbation ${ }^{6}$} \\
\hline & \multirow{2}{*}{$\begin{array}{l}\text { Adjusted incidence } \\
\text { rate ratio }\end{array}$} & \multirow[t]{2}{*}{$\mathbf{N}$} & \multicolumn{2}{|l|}{$95 \% \mathrm{Cl}$} & \multirow[t]{2}{*}{$P$-value } \\
\hline & & & Lower & Upper & \\
\hline $\begin{array}{l}\text { Sedentary lifestyle } \\
\text { PA }\end{array}$ & $\begin{array}{l}1 \\
0.72\end{array}$ & $\begin{array}{l}219 \\
2,156\end{array}$ & 0.53 & 0.97 & 0.033 \\
\hline
\end{tabular}

Abbreviations: GOLD, Global Initiative for Chronic Obstructive Lung Disease; N, total number of patients per PA level; PA, Physical activity; Sedentary, sedentary lifestyle. 
exacerbations was calculated. These data were assumed to be representative of the sedentary arm.

To have the same set of evidence for the PA arm, we adjusted the sedentary data using the adjusted risk of exacerbation of the combined levels of PA (low/moderate/high PA) reported by Garcia-Aymerich et al (Table 4). ${ }^{6}$

\section{Mortality}

COPD patients have different mortality profiles depending on the disease severity and age. Boutou et $\mathrm{al}^{23}$ reported survival curves, adjusted for age, and other statistically significant predictors stratified by disease severity as described by the 2017 GOLD classification for airflow limitation. For each of the curves, linear regression equations were determined per GOLD stage to predict the cumulative survival risk.

Patients in the study of Boutou et $\mathrm{al}^{23}$ had an average age of 62 years and were followed up until 75 years of age on average. Thus, the above numbers had to be corrected for younger and older patients by using gender- and age-specific UK life tables. The available mortalities from Boutou et $\mathrm{al}^{23}$ between 62 and 75 years were compared with the UK life tables and the ratios were calculated. By multiplying the mortality of the general population at other ages and the corresponding ratios, age- and gender-dependent mortality for COPD was determined for each GOLD state. Finally, to estimate the risk of dying in the PA arm, we adjusted the risk of death of the sedentary arm, by applying the adjusted HR for all-cause mortality from Garcia-Aymerich et al $(=0.76){ }^{6}$

\section{Pulmonary rehabilitation}

As mentioned earlier, PR has a positive impact on disease progression after severe exacerbations. However, it is not applied universally. Therefore, we studied two extremes, where $0 \%$ and $100 \%$ of patients had PR program. PR usually includes a smoking cessation program. In Scotland, after 1 month, 37\% of smokers successfully completed the smoking cessation program. ${ }^{24}$

\section{QOL}

European Quality of Life-5 Dimensions (EQ-5D) for the different COPD severity stages were taken from Rutten-Van Mölken et $\mathrm{al}^{25}$ for the base case analysis. This study analyzed a subset of 1,235 patients of the UPLIFT trial and concluded a negative association between the severity of COPD and utility scores. Utility scores were reported for three GOLDdefined COPD severity stages, moderate, severe, and very severe for the UK and the USA. As mild COPD was missing, a conservative assumption was taken, assuming that this utility would be the same as in the moderate health state. The UK values were selected for this analysis.
The values by Wacker et $\mathrm{al}^{26}$ were used in the scenario analysis (Table 5). This study used the German COPD data COSYCONET of 2,291 subjects in COPD GOLD stages I-IV. They concluded that all health-related quality of life (HRQL) instruments reflect considerable impairment of HRQL in COPD patients, worsening with increasing COPD grade and number of comorbidities.

The impact that exacerbations of COPD have on QOL has been reported previously. As QOL instruments are usually administered during a stable phase of the disease, it is difficult to find the utility data specific to these events. ${ }^{25}$ As an alternative, many studies ${ }^{13,22,27,28}$ opted to use specific utility corrections for each type of exacerbation. The corrections used in the current analysis are 15\% and 50\% in case of moderate or severe exacerbations, respectively (Table 5). The first was taken from Spencer et $\mathrm{al}^{29}$ and the second from Paterson et al, ${ }^{30}$ both of which were reported by Oostenbrink et al. ${ }^{28}$

\section{Costs}

A monthly maintenance cost was associated with each health state and an acute cost was applied to each event. All cost data were taken from Ramos et $\mathrm{al}^{15}$ and updated to 2017 (Table 5). PA cost was assumed to be null in the base case; however, a threshold analysis was conducted to determine the price up to which PA is cost saving and cost-effective while considering a willingness-to-pay threshold of $£ 20,000$ per quality-adjusted life years (QALY).

The cost of PR derived from Healthcare Improvement Scotland 2011 (£249) was inflated in 2017 (£275.32). ${ }^{25}$

\section{Deterministic outcomes}

Outcomes of the $\mathrm{CE}$ analysis are reported as: number of hospitalizations due to severe exacerbations, mortality at 5 years, incremental life years (LY), incremental QALYs, incremental total costs, cost per life-year gained (incremental cost-effectiveness ratio [ICER]), cost per quality-adjusted life year gained (incremental cost-utility ratio [ICUR]), and net monetary benefit (NMB). Future costs and effects are discounted at $3.5 \%$ per year.

\section{Uncertainty analysis}

Scenario analysis, one-way sensitivity analysis (OWSA), and probabilistic sensitivity analysis (PSA) were conducted to evaluate the uncertainty associated with the assumptions and input data considered in this study.

Scenario analysis explores the uncertainty surrounding specific assumptions considered in the base case analysis. Therefore, the following scenarios were assessed: shorter 
Table 5 Economic data

\begin{tabular}{|c|c|c|c|c|}
\hline \multicolumn{5}{|l|}{ Cost of data in $t$} \\
\hline \multicolumn{5}{|c|}{ Monthly cost of maintenance per health state ${ }^{15}$} \\
\hline & \multirow[t]{2}{*}{ Mean } & \multicolumn{2}{|l|}{ OWSA } & \multirow{2}{*}{$\begin{array}{l}\text { PSA } \\
\text { distribution* }\end{array}$} \\
\hline & & Lower & Upper & \\
\hline GOLD stage I & 7.79 & 5.45 & 10.12 & Gamma \\
\hline GOLD stage II & 23.15 & 16.21 & 30.10 & \\
\hline GOLD stage III & 57.00 & 39.90 & 74.10 & $* *$ \\
\hline GOLD stage IV & 167.16 & 117.01 & 217.31 & $* *$ \\
\hline \multirow[t]{2}{*}{ Cost of events in $t^{15}$} & \multirow[t]{2}{*}{ Mean } & \multicolumn{2}{|l|}{ OWSA } & \multirow{2}{*}{$\begin{array}{l}\text { PSA } \\
\text { distribution* }\end{array}$} \\
\hline & & Lower & Upper & \\
\hline Severe exacerbation & I,47।.02 & $\mathrm{I}, 097.72$ & I,740.90 & Gamma \\
\hline Moderate exacerbation & 70.30 & 42.26 & 91.73 & Gamma \\
\hline Utility data & GOLD stage I & GOLD stage II & GOLD stage III & GOLD stage IV \\
\hline \multicolumn{5}{|l|}{ EQ-5D"25 } \\
\hline $\mathrm{N}$ & & 622 & 513 & 91 \\
\hline Mean & 0.787 & 0.787 & 0.75 & 0.647 \\
\hline $95 \% \mathrm{Cl}$ & $(0.77 I ; 0.802)$ & $(0.77 I ; 0.802)$ & $(0.73 I ; 0.768)$ & $(0.598 ; 0.695)$ \\
\hline \multicolumn{5}{|l|}{$E Q-5 D^{26}$} \\
\hline $\mathrm{N}$ & 206 & 962 & 874 & 249 \\
\hline Mean & 0.85 & 0.84 & 0.81 & 0.74 \\
\hline $95 \% \mathrm{Cl}$ & $(0.83 ; 0.87)$ & $(0.83 ; 0.85)$ & $(0.80 ; 0.82)$ & $(0.7 I ; 0.77)$ \\
\hline \multicolumn{5}{|l|}{ Utility correction $^{28}$} \\
\hline \multirow[t]{2}{*}{ Exacerbation type } & Moderate & 0.85 & & \\
\hline & Severe & 0.5 & & \\
\hline
\end{tabular}

Notes: *Due to lack of detailed information on the uncertainty around management and event unit costs, it was assumed that the SD would be equal to the mean value $\left(\mathrm{SD}=\right.$ mean). Alpha and beta of the Gamma distribution were estimated as (mean/SD) ${ }^{2}$ and $\left(\mathrm{SD}^{2} / \mathrm{mean}\right)$, respectively. All costs were inflated to $20 \mathrm{I}$. **The probabilistic values of maintenance costs of GOLD stage II, III, and IV were calculated as the ratio between the probabilistic value of GOLD stage I and magnitude cost ratio between GOLD I and the remaining GOLD stages (2.97, 7.32, and 21.47).

Abbreviations: EQ-5D, European Quality of Life-5 Dimensions Questionnaire; GOLD, Global Initiative for Chronic Obstructive Lung Disease; N, total number of patients per PA level; OWSA, one-way sensitivity analysis; PSA, probabilistic sensitivity analysis.

time horizons (5-25 years); changing patient baseline characteristics to those reported by Garcia-Aymerich et $\mathrm{al}^{5,6}$ (younger population); patients starting in an early stage of COPD $(50 \%$ in GOLD I + 50\% in GOLD II); patients starting in a later stage of COPD $(50 \%$ in GOLD III $+50 \%$ in GOLD IV); excluding the minimum $\mathrm{FEV}_{1}$ compatible with life $\left(10 \%\right.$ of predicted $\left.\mathrm{FEV}_{1}\right)$; using baseline utilities per GOLD stage from Wacker et al; ${ }^{26}$ after a severe exacerbation, all patients follow a PR program; $17.3 \%$ of exacerbations were severe exacerbations. In order to assess the cost at which PA would be cost-saving or cost-effective after 1 year of therapy and in the long-term, price scenarios for PA were analyzed at 1 and 35 years (see the "Scenario analysis" section).

The OWSA allows for the introduction of variability to one parameter within plausible fixed limits, while holding all other parameters fixed in order to assess the effect on the base case ICUR. Outcomes from this analysis are shown in a tornado diagram (Figure 2).

In a PSA, all inputs are varied simultaneously in order to further explore the precision of the model outcome. For the
PSA, the bootstrap analysis using the Monte Carlo method of 1,000 iterations was applied. Outcomes of this analysis are shown in the format of a cost-effectiveness (CE) plane.

For both OWSA and PSA, where uncertainty around parameters values was reported in the data sources, these details were used. Otherwise, assumptions were considered to determine the minimum and maximum values and parameters of distributions.

\section{Results}

The results of the CEA of "PA" vs "sedentary lifestyle" after 35 years are summarized in Table 6. Compared with sedentary lifestyle, the slowdown of the lung function decline and the lower risk of exacerbations and of dying in the PA arm led to savings in terms of event costs $(-£ 2,568)$, lower mortality $(-6 \%)$, and lower number of hospitalizations $(-2 \%)$. Furthermore, patients remain in the lower severity levels of the disease for a longer time, accumulate increased life years $(+0.82)$ and more QALYs $(+0.66)$ compared to sedentary lifestyle. As a result of a lower mortality, management costs are higher in the PA arm compared to sedentary lifestyle. 


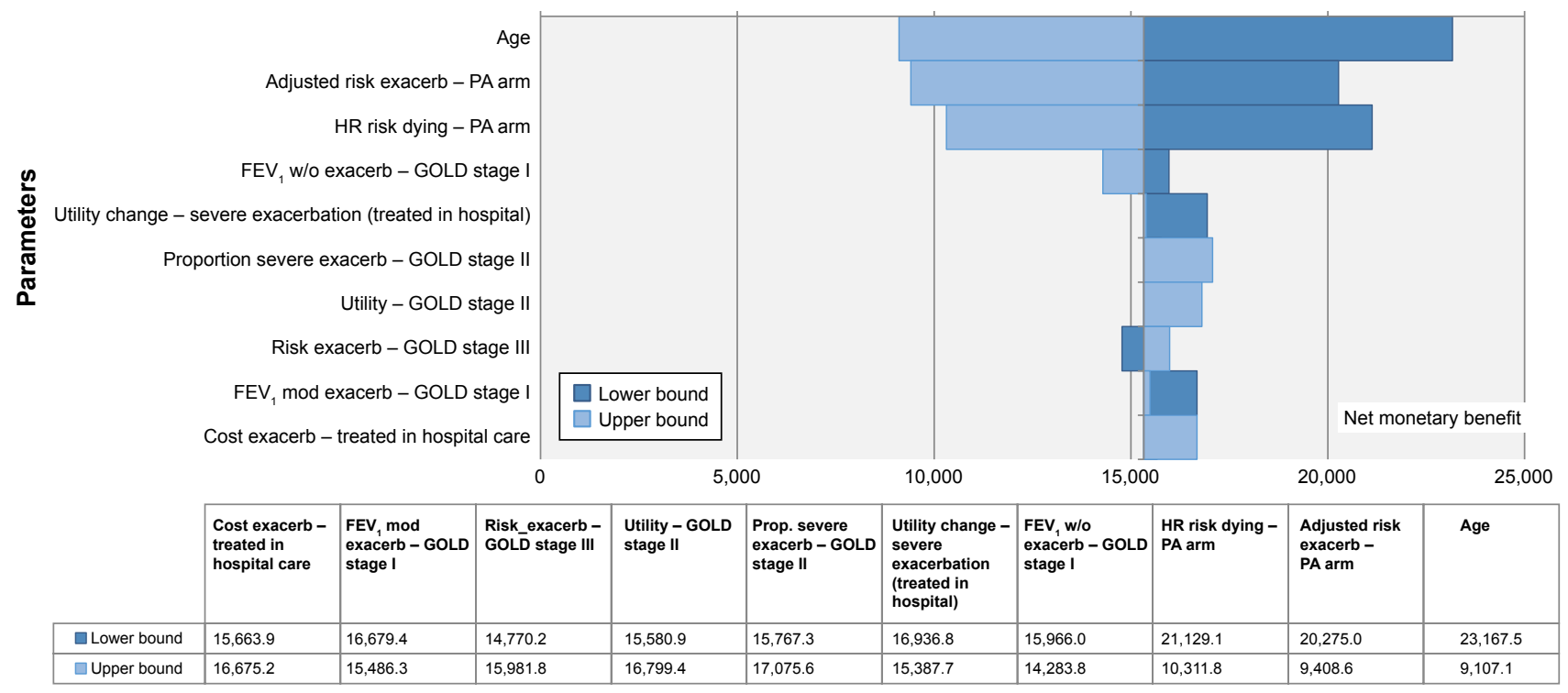

Figure $\mathbf{2}$ Tornado diagram of PA vs sedentary lifestyle measured in terms of NMB. Note: Cost data presented in $\ell$.

Abbreviations: GOLD, Global Initiative for Chronic Obstructive Lung Disease; mod, moderate; NMB, net monetary benefit; PA, physical activity; exacerb, exacerbation; w/o, without.

Nevertheless, this increase was offset by savings in event costs, resulting in a total discounted cost savings of $-£ 2,568$. These outcomes resulted in a dominant ICER and ICUR. For a willingness to pay of $£ 20,000$ per QALY, the NMB was $£ 15,807$ (Table 6).

\section{Scenario analysis}

All the different scenarios tested confirmed the dominance of PA vs sedentary lifestyle.

By comparing three age scenarios, 1) patients starting at an early stage of COPD ( $50 \%$ in GOLD I $+50 \%$ in GOLD II), 2) patients starting at a later stage of COPD $(50 \%$ in GOLD $\mathrm{III}+50 \%$ in GOLD IV), and 3 ) younger patients as described Garcia-Aymerich et al, ${ }^{5,6}$ over a longer term, results show that PA is more beneficial in younger and less severe patients, providing more savings, LY, and QALY gains.

In the scenario where $17.3 \%$ of exacerbations are assumed to be severe in all GOLD stages, PA continues to be costsaving (-£1,854), with additional life-year gains $(0.972)$ and additional QALY gains (0.787), keeping the dominant profile of PA compared to sedentary lifestyle.

Applying PR program to all severe exacerbations, the results continue to show that PA is a cost-saving (incremental discounted costs $=-£ 2,890$ ) and the dominant strategy compared with the sedentary arm. Due to the inclusion of the PR program, intervention costs are no longer null in both the arms ( $£ 2,765$ vs $£ 3,372$ ). However, in the case of the PA arm, they are smaller due to a reduced number of exacerbations.
By excluding the minimum $\mathrm{FEV}_{1}$ compatible with life, results changed marginally, as its impact is reflected in both the arms equally. Both the arms had an increase of $0.1 \mathrm{LY}$ after 35 years.

Table 6 Cost-effectiveness results

\begin{tabular}{|c|c|c|}
\hline & PA & $\begin{array}{l}\text { Sedentary } \\
\text { lifestyle }\end{array}$ \\
\hline \multicolumn{3}{|l|}{ Breakdown of costs } \\
\hline Intervention cost $(£)$ & - & - \\
\hline Management cost $(\ell)$ & 5,048 & 4,797 \\
\hline Event cost $(£)$ & $|5,32|$ & 18,435 \\
\hline Total cost (not discounted) $(£)$ & 20,368 & 23,232 \\
\hline \multicolumn{3}{|l|}{ Clinical results } \\
\hline Risk of dying (end of time horizon) & $100 \%$ & $100 \%$ \\
\hline Mortality at 5 years & $44.90 \%$ & $51.48 \%$ \\
\hline Number of hospitalizations due & 10.11 & 12.28 \\
\hline to exacerbations & & \\
\hline Number of years in GOLD I & 0.38 & 0.28 \\
\hline Number of years in GOLD II & 4.02 & 3.24 \\
\hline Number of years in GOLD III & 2.57 & 2.17 \\
\hline Number of years in GOLD IV & 1.07 & 1.19 \\
\hline $\begin{array}{l}\text { Cost-effectiveness } \\
\text { results }\end{array}$ & PA & $\begin{array}{l}\text { Sedentary } \\
\text { lifestyle }\end{array}$ \\
\hline Total discounted cost $(£)$ & 15,925 & 18,493 \\
\hline Total discounted LY & 6.47 & 5.646 \\
\hline Total discounted QALYs & 4.796 & 4.134 \\
\hline Incremental cost $(£)$ & $-2,568$ & \\
\hline Incremental LY & 0.824 & \\
\hline Incremental QALYs & 0.662 & \\
\hline ICER & Dominant & \\
\hline ICUR & Dominant & \\
\hline NMB $(£)$ for a willingness to pay of $£ 20,000$ & 15,807 & \\
\hline
\end{tabular}

Note: - indicates no price was applied for the intervention.

Abbreviations: GOLD, Global Initiative for Chronic Obstructive Lung Disease; ICER, incremental cost-effectiveness ratio; ICUR, incremental cost-utility ratio; LY, life years; NMB, net monetary benefit; PA, physical activity; QALY, qualityadjusted life-years. 


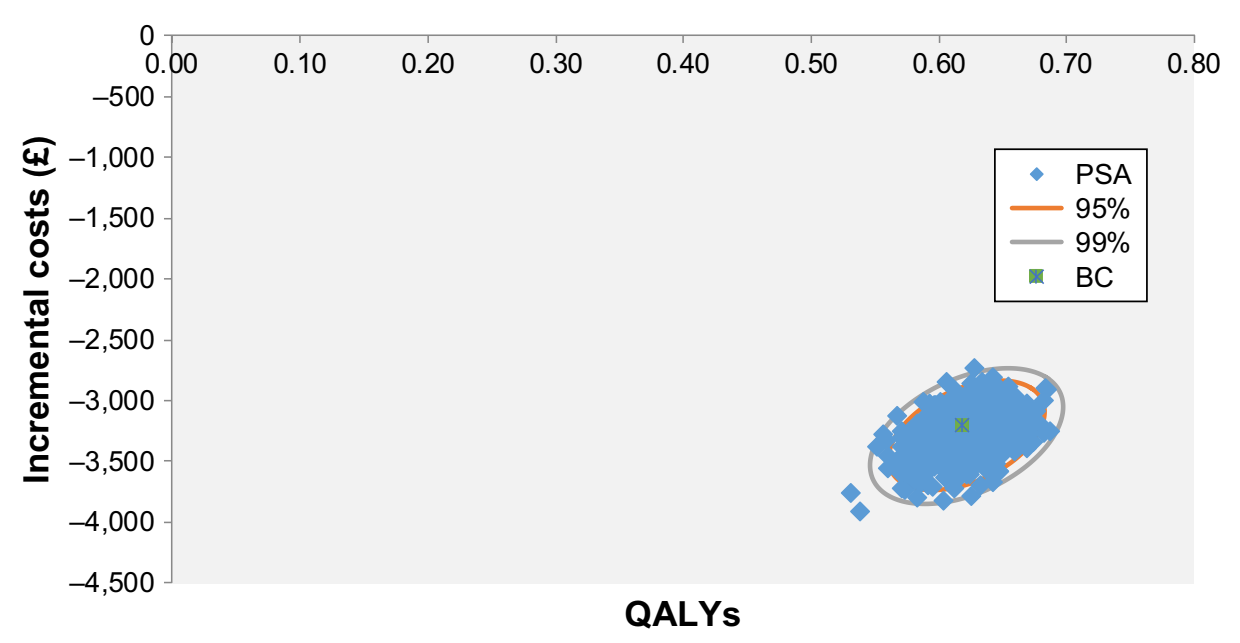

Figure 3 Cost-effectiveness plane of PA vs sedentary lifestyle measured.

Abbreviations: PA, physical activity; PSA, probabilistic sensitivity analysis; QALYs, quality-adjusted life years; BC, base case.

To assess the impact of the baseline utilities per GOLD state on the outcomes, data from Wacker et $\mathrm{al}^{26}$ were used instead of Rutten-Van Mölken et al. ${ }^{25}$ In this analysis, QALY gains slightly increase to 0.694 after 35 years.

Pricing analyses for the monthly cost of PA revealed that PA would be cost-saving with a monthly price below $£ 51$ and $£ 35$ or cost-effective below $£ 83$ and $£ 202$, after 1 year of intervention and in the long-term, respectively.

\section{Uncertainty analysis}

OWSA outcomes were shown in term of NMB, as ICURs were mostly negative (Figure 2). The NMB ranged between $£ 19,000$ and $£ 24,000$ (Figure 2). The parameters with the greatest impact were age, impact of PA on the risk of dying, and adjusted risk of exacerbation treated in hospital. PSA results showed that in $100 \%$ of Monte Carlo simulations, PA was dominant vs sedentary lifestyle, independently of any willingness to pay (Figure 3).

\section{Discussion}

This health economic evaluation demonstrated that regular PA in COPD patients is likely to be a dominant alternative from the National Health Service (NHS) perspective in the UK. PA is estimated to be cost-saving $(-£ 2,568)$ and to yield more QALYs (0.82) and LYs (0.66). The biggest cost savings were seen in the first years of regular PA, due to its benefit in reducing exacerbations. Additionally, the extended sensitivity analyses support these findings.

Note that in this study, PA was defined as an intervention, where patients perform regular daily activity ranging from patients engaging in light PA (eg, walking or biking) for $<2$ hours/week to highly vigorous PA for $>4$ hours per week. PR is a short-term intervention, which may be prescribed by the physician, usually after an acute exacerbation of COPD, and therefore, this event is included in the model as such.

A key analysis was to test the maximum price level at which PA is still cost-saving and cost-effective and, as such, provides the payer with an idea on how much could be spent while remaining good value for money. This analysis indicated that PA is a cost-saving and cost-effective intervention for a monthly cost below $£ 35$ and $£ 202$ in the long term, and $£ 51$ and $£ 83$ after 1 year of intervention, respectively. Within this range, monthly prescriptions to a fitness club are expected to be covered. In this context, health care specialists could suggest patients perform light, moderate, or vigorous PA by subscribing to a fitness club or to an exercise communitybased center and design specific exercise plans according to patient's requirements. This could be particularly important in cold and rainy countries, where outside activities might be scarce for COPD patients. In some countries, the setup of specific PA programs under supervision of trained physiotherapists is already very common, for example, for coronary artery disease patients. However, this ideal situation is likely to be difficult to organize at under $£ 193$ per patient per month, assuming 4-8 sessions per month with availability of a physiotherapist and a medical doctor.

To evaluate the impact of model uncertainty and the robustness of the results, OWSA and PSA were performed on drivers of the model. Overall the sensitivity analyses demonstrated the robustness of the results and revealed that the main drivers of this Markov simulation model were age, impact of PA on risk of dying, and the adjusted risk of exacerbation treated in hospital. The PSA showed that PA is $100 \%$ likely to be dominant in COPD patients for a 35-year time horizon. 
The COPD value pyramid ${ }^{31}$ is a tool developed to reflect the cost per QALY of interventions in COPD and to guide health care organizations to promote, audit, and ensure adequate commissioning of nonpharmacological interventions in COPD. The results obtained in the current study show that an essential nonpharmacological intervention, regular PA, is missing at the base.

The current Markov microsimulation model is able to simulate the evolution of $\mathrm{FEV}_{1}$ over time, to describe the progression of the COPD patients by tracing the movement of patients within the different health states over time, to reflect the speed of progression of the disease by adding further trackers to the Markov engine, to count the number of COPD events and correct the speed of disease progression when this occurs, and identifies when patients change their smoking status and die. An important drawback of this method (microsimulation model with 5,000 patients) is the high demand of computation power when individual and joint uncertainty of all parameters are assessed using OWSA and PSA. The methodology and assumptions applied in this analysis are discussed below.

The progression of the COPD and the criteria used to observe the patients' movement between health states follow the 2017 GOLD classification for severity ${ }^{32}$ of airflow obstruction. This classification also uses symptoms (eg, dyspnea, cough) that were not included in our study.

Several predicative equations are available to predict the lung function capacity. ${ }^{16,32-38}$ The British Thoracic Society COPD consortium equations ${ }^{16}$ were found to best suit the scope of this project as they addressed a UK population. The selection of the risk equation has a modest impact on the final results as it is the same in all treatment arms.

Since the UK was the base case country, UK baseline characteristics reported by Haughney et $\mathrm{al}^{13}$ were used. However, this population is older and more ill than the population that was used for the efficacy data. ${ }^{5,6}$ The scenario based on the Garcia-Aymerich et al population demonstrated dominance of PA with better clinical benefits. ${ }^{5,6}$ This is in line with the published evidence indicating that PA benefit is reduced in the more severe COPD stages. ${ }^{17}$

The Garcia-Aymerich et al ${ }^{5,6}$ studies report the best evidence demonstrating the benefit of $\mathrm{PA}$ on $\mathrm{FEV}_{1}$ decline, the risk of exacerbation and mortality. Unfortunately, the population in Garcia-Aymerich et al ${ }^{5,6}$ included only a small proportion of COPD patients. This small set of patients was the focus of Garcia-Aymerich et al..$^{5}$ It is questionable whether it is reasonable to assume that $\mathrm{FEV}_{1}$ decline is altered in the same way in COPD patients. However, the bivariate analysis ${ }^{6}$ conducted by the authors showed that the $\mathrm{FEV}_{1}$ decline was higher for lower $\mathrm{FEV}_{1}$ levels at baseline, suggesting that the impact of PA on FEV 1 could even be superior. In the current analysis, the evidence reported by the authors was applied in GOLD stage I.

Since no statistically significant impact was observed for moderate exacerbations on $\mathrm{FEV}_{1}$ decline for all GOLD stages nor for severe exacerbation for GOLD stage IV patients, we conservatively considered the impact to be null.

Exacerbation data per GOLD stage were derived from Karabis et al. ${ }^{22}$ In this model, a higher proportion of the recorded exacerbations were severe. However, other studies show the opposite trend..$^{39,40}$ A higher proportion of severe exacerbations led to an overall faster progression of the disease, affecting the results by lowering the life expectancy in both the arms and also in the arm with the highest risk of exacerbation, which in the case is the sedentary arm of our analysis. We tested this assumption using the proportion of severe exacerbation reported by Pavord et al (17.3\%). ${ }^{40}$ Analysis showed that PA is still cost-saving, though less $(-£ 1,854)$ compared with sedentary lifestyle.

The TLR provided evidence that the majority of COPD patients hospitalized for an exacerbation follow a PR program to minimize the effect of the event on the lung function capacity. Elkhateeb et al reported that the added benefit of a 6-8 week PR program was $8.8 \mathrm{~mL} .{ }^{21}$ Other data were found in the literature for short-term PR programs; however, the reported benefits were considered unrealistic - the reported benefit was considered too high-eliminating the progression of the disease for 3 years or the impact of severe exacerbation entirely. ${ }^{19,20}$

In the case of a smoker, if a PR program has been started, we assume that smoking cessation is included in the program with a success rate of $37 \%$, though this rate declines over time. ${ }^{24}$ Nevertheless, the recurrence of smoking is not included in the model.

Mortality is one of the most important factors determining the differences of $\mathrm{CE}$ outcomes for treatments in the management of COPD. ${ }^{41}$ In the current analysis, the risk of death was defined based on UK life tables ${ }^{42}$ and mortality data per GOLD stage, ${ }^{23}$ which was later adjusted for the different PA levels. ${ }^{6}$ Both the sets ${ }^{23,42}$ include data on fatal exacerbations, and therefore, the risk of fatal exacerbations can be overestimated. Additionally, at $\mathrm{FEV}_{1}$ values below $10 \%$ of a patient's lung function, it was assumed to be not compatible with life. ${ }^{18} \mathrm{~A}$ scenario analysis showed that the effect of using this minimum $\mathrm{FEV}_{1}$ value is modest.

Finally, adherence to PA and classic comorbidities (eg, pulmonary hypertension and right heart failure, coronary 
heart disease, atrial fibrillation, venous thromboembolism) associated with COPD were not included.

The economic and clinical benefits of PA have been studied in many other disease areas (eg, obesity, cancer, coronary heart disease, stroke, type 2 diabetes, breast and colon cancer). ${ }^{43-45} \mathrm{CE}$ studies on PR programs have been published elsewhere. ${ }^{46-50}$ Nevertheless, CE studies on PA as a regular intervention were not found; hence, to our knowledge, this study is the first to explore PA vs sedentary lifestyle in COPD patients. Therefore, it is not possible to compare our findings with other studies. A very recent study was identified that assesses the effects of sedentary life and PA after 6 weeks of home-based coaching intervention. ${ }^{51}$ The authors concluded that in severe COPD patients, this intervention may reduce lung disease-related health care utilization. These findings further support our study results; however, they are related to a short-term PA intervention, whereas our study focused on the long-term effects of PA.

The efficacy data used in the model were derived from a TLR, of which none of the identified studies was a randomized controlled trial that assessed the impact of PA in COPD patients. Thus, the evidence used in this model only comes from cross-sectional or observational longitudinal literature. To further validate the value of PA in COPD patients, an interventional study to compare PA with clearly defined levels (in duration and intensity) against sedentary lifestyle, split per GOLD class, and with a follow-up of at least 5 years is required. Data collection should include clinical outcomes that demonstrate the benefits of PA in COPD patients which could be used to populate this CE model. Examples of such outcomes are: $\mathrm{FEV}_{1}$ decline over time with and without exacerbations, $\mathrm{FEV}_{1}$ decline over time per exacerbations type, number of exacerbations, number of hospitalizations due to severe exacerbation, mortality, drug use, and smoking behavior.

\section{Conclusion}

Our study concludes that if UK patients with COPD perform regular PA, this is likely to bring long-term clinical benefits and cost-savings to the UK NHS when compared to having COPD patients with a sedentary lifestyle. This suggests that PA should be recommended in the management of these patients.

\section{Acknowledgments}

This submission represents the original work not being considered by any other journal. This study was sponsored by AstraZeneca SA.

\section{Author contributions}

MR, LG, ML, PS, and JH made substantial contributions to the conception and design of the study, or acquisition of data, or analysis and interpretation of data. All authors contributed to data analysis, drafting and revising the article, gave final approval of the version to be published, and agree to be accountable for all aspects of the work.

\section{Disclosure}

$\mathrm{JH}$ received consulting fees for providing information on the management of COPD in the UK. MR, ML, and LG are employees of IQVIA and received consulting fees for developing the model and/or writing the manuscript. PS and AMC are employees of AstraZeneca. The authors report no other conflicts of interest in this work.

\section{References}

1. Global Initiative for Chronic Obstructive Lung Disease. Pocket Guide to COPD Diagnosis, Management, and Prevention - A Guide to COPD Diagnosis, Management, and Prevention; 2017. Available from: http:// goldcopd.org/pocket-guide-copd-diagnosis-management-prevention2016/. Accessed November 23, 2017.

2. WHO. Chronic obstructive pulmonary disease (COPD). Available from: http://www.who.int/respiratory/copd/en/. Accessed November 23, 2017.

3. Corhay JL, Dang DN, van Cauwenberge H, Louis R. Pulmonary rehabilitation and COPD: providing patients a good environment for optimizing therapy. Int J Chron Obstruct Pulmon Dis. 2014;9:27-39.

4. Snell N, Strachan D, Hubbard R, Gibson J, Gruffydd-Jones K, Jarrold I. S32 Epidemiology of chronic obstructive pulmonary disease (COPD) in the uk: findings from the british lung foundation's 'respiratory health of the nation' project. Thorax. 2016;71(Suppl 3):A20-A20.

5. Garcia-Aymerich J, Lange P, Benet M, Schnohr P, Antó JM. Regular physical activity modifies smoking-related lung function decline and reduces risk of chronic obstructive pulmonary disease: a population-based cohort study. Am J Respir Crit Care Med. 2007;175(5):458-463.

6. Garcia-Aymerich J, Lange P, Benet M, Schnohr P, Antó JM. Regular physical activity reduces hospital admission and mortality in chronic obstructive pulmonary disease: a population based cohort study. Thorax. 2006;61(9):772-778.

7. Zafari Z, Bryan S, Sin DD, Conte T, Khakban R, Sadatsafavi M. A Systematic Review of Health Economics Simulation Models of Chronic Obstructive Pulmonary Disease. Value Health. 2017;20(1):152-162.

8. Exuzides A, Colby C, Briggs A, Riseborough N, Baker TM, Ismaila A Some statistical considerations in estimating a disease progression model for chronic obstructive pulmonary disease (COPD). Value in Health. 2014;17(3):A183

9. Punekar YS, Roberts G, Ismaila A, O'Leary M. Cost-effectiveness of umeclidinium/vilanterol combination therapy compared to tiotropium monotherapy among symptomatic patients with chronic obstructive pulmonary disease in the UK. Cost Eff Resour Alloc CE; 2015. Available from: https://www.ncbi.nlm.nih.gov/pmc/articles/PMC4676898/. Accessed November 25, 2017.

10. Briggs AH, Baker T, Risebrough NA, et al. Development of the Galaxy Chronic Obstructive Pulmonary Disease (COPD) Model Using Data from ECLIPSE: Internal Validation of a Linked-Equations Cohort Model. Med Decis Making. 2017;37(4):469-480.

11. Tabberer M, Gonzalez-Mcquire S, Muellerova H, et al. Development of a Conceptual Model of Disease Progression for Use in Economic Modeling of Chronic Obstructive Pulmonary Disease. Med Decis Making. 2017;37(4):440-452. 
12. Miravitlles M, Gáldiz JB, Huerta A, Villacampa A, Carcedo D, Garcia-Rio F. Cost-effectiveness of combination therapy umeclidinium/ vilanterol versus tiotropium in symptomatic COPD Spanish patients. Int J Chron Obstruct Pulmon Dis. 2016;11:123-132.

13. Haughney J, Gruffydd-Jones K, Roberts J, Lee AJ, Hardwell A, Mcgarvey L. The distribution of COPD in UK general practice using the new GOLD classification. Eur Respir J. 2014;43(4):993-1002.

14. National Health Service. Health Survey for England - 2009, Trend tables; 2010. Available from: https://digital.nhs.uk/catalogue/ PUB00445. Accessed December 17, 2017.

15. Ramos M, Haughney J, Henry N, Lindner L, Lamotte M. Cost versus utility of aclidinium bromide $400 \mu \mathrm{g}$ plus formoterol fumarate dihydrate $12 \mu \mathrm{g}$ compared to aclidinium bromide $400 \mu \mathrm{g}$ alone in the management of moderate-to-severe COPD. Clinicoecon Outcomes Res. 2016; $8: 445-456$.

16. British Thoracic Society COPD Consortium. Spirometry in practice. A Practical Guide to Using Spirometry in Primary Care. Second ed; 2005. https://www.brit-thoracic.org.uk/document-library/delivery-ofrespiratory-care/spirometry/spirometry-in-practice-a-practical-guide(2005)/. Accessed October 10, 2018.

17. Dransfield MT, Kunisaki KM, Strand MJ, et al. Acute Exacerbations and Lung Function Loss in Smokers with and without Chronic Obstructive Pulmonary Disease. Am J Respir Crit Care Med. 2017;195(3):324-330.

18. Fletcher C, Peto R. The natural history of chronic airflow obstruction. Br Med J. 1977;1(6077):1645-1648.

19. Ali MS, Talwar D, Jain SK. The effect of a short-term pulmonary rehabilitation on exercise capacity and quality of life in patients hospitalised with acute exacerbation of chronic obstructive pulmonary disease. Indian J Chest Dis Allied Sci. 2014;56(1):13-19.

20. Incorvaia $C$, Russo A, Foresi A, et al. Effects of pulmonary rehabilitation on lung function in chronic obstructive pulmonary disease: the FIRST study. Eur J Phys Rehabil Med. 2014;50(4):419-426.

21. Elkhateeb NB, Elhadidi AA, Masood HH, Mohammed AR. Pulmonary rehabilitation in chronic obstructive pulmonary disease. Egypt J Chest Dis Tuberc. 2015;64(2):359-369.

22. Karabis A, Mocarski M, Eijgelshoven I, Bergman G. Economic evaluation of aclidinium bromide in the management of moderate to severe COPD: an analysis over 5 years. Clinicoecon Outcomes Res. 2014; 6:175-185.

23. Boutou AK, Shrikrishna D, Tanner RJ, et al. Lung function indices for predicting mortality in COPD. Eur Respir J. 2013;42(3): 616-625.

24. NHS. NHS Smoking Cessation Services (Scotland). Information Services Division, Publication report; 2016. Available from: http:// www.isdscotland.org/Health-Topics/Public-Health/Publications/201610-04/2016-10-04-SmokingCessation-Report.pdf. Accessed October $10,2018$.

25. Rutten-van Mölken MP, Oostenbrink JB, Tashkin DP, Burkhart D, Monz BU. Does quality of life of COPD patients as measured by the generic EuroQol five-dimension questionnaire differentiate between COPD severity stages? Chest. 2006;130(4):1117-1128.

26. Wacker ME, Jörres RA, Karch A, et al. Assessing health-related quality of life in COPD: comparing generic and disease-specific instruments with focus on comorbidities. BMC Pulm Med. 2016;16(1):70.

27. Earnshaw SR, Wilson MR, Dalal AA, et al. Cost-effectiveness of fluticasone propionate/salmeterol $(500 / 50 \mathrm{microg})$ in the treatment of COPD. Respir Med. 2009;103(1):12-21.

28. Oostenbrink JB, Rutten-van Mölken MP, Monz BU, Fitzgerald JM. Probabilistic Markov model to assess the cost-effectiveness of bronchodilator therapy in COPD patients in different countries. Value Health. 2005;8(1):32-46.

29. Spencer M, Briggs AH, Grossman RF, Rance L. Development of an economic model to assess the cost effectiveness of treatment interventions for chronic obstructive pulmonary disease. Pharmacoeconomics. 2005;23(6):619-637.
30. Paterson C, Langan CE, Mckaig GA, et al. Assessing patient outcomes in acute exacerbations of chronic bronchitis: the measure your medical outcome profile (MYMOP), medical outcomes study 6-item general health survey (MOS-6A) and EuroQol (EQ-5D). Qual Life Res. 2000;9(5):521-527.

31. NHS Network. LRN's COPD Value Pyramid. Available from: https:// www.networks.nhs.uk/nhs-networks/london-lungs/latest-edition-ofthorax-publication. Accessed December 17, 2017.

32. Langhammer A, Johnsen R, Gulsvik A, Holmen TL, Bjermer L. Forced spirometry reference values for Norwegian adults: the Bronchial Obstruction in Nord-Trøndelag Study. Eur Respir J. 2001;18(5): 770-779.

33. Hedenström H, Malmberg P, Fridriksson HV. Reference values for lung function tests in men: regression equations with smoking variables. Ups J Med Sci. 1986;91(3):299-310.

34. Roca J, Burgos F, Sunyer J, et al. References values for forced spirometry. Group of the European Community Respiratory Health Survey. Eur Respir J. 1998;11(6):1354-1362.

35. Falaschetti E, Laiho J, Primatesta P, Purdon S. Prediction equations for normal and low lung function from the Health Survey for England. Eur Respir J. 2004;23(3):456-463.

36. Hankinson JL, Odencrantz JR, Fedan KB. Spirometric reference values from a sample of the general U.S. population. Am J Respir Crit Care Med. 1999;159(1):179-187.

37. Quanjer PH, Tammeling GJ, Cotes JE, Pedersen OF, Peslin R, Yernault JC. Lung volumes and forced ventilatory flows. Eur Respir J. 1993;6 Suppl 16:5-40.

38. Quanjer PH, Stanojevic S, Cole TJ, et al. Multi-ethnic reference values for spirometry for the 3-95-yr age range: the global lung function 2012 equations. Eur Respir J. 2012;40(6):1324-1343.

39. Vestbo J, Papi A, Corradi M, et al. Single inhaler extrafine triple therapy versus long-acting muscarinic antagonist therapy for chronic obstructive pulmonary disease (TRINITY): a double-blind, parallel group, randomised controlled trial. Lancet. 2017;389(10082):1919-1929.

40. Pavord ID, Jones PW, Burgel PR, Rabe KF. Exacerbations of COPD. Int J Chron Obstruct Pulmon Dis. 2016;11 Spec Iss:21-30.

41. Hoogendoorn M, Feenstra TL, Asukai Y, et al. Cost-effectiveness models for chronic obstructive pulmonary disease: cross-model comparison of hypothetical treatment scenarios. Value Health. 2014;17(5): 525-536.

42. Office of National Statistics. National life tables 2012-2014; 2010. Available from: http://webarchive nationalarchives.gov. uk/20160106035247/http://www.ons.gov.uk/ons/publications/ re-reference-tables.html? edition=tcm\%3A77-394848. Accessed November 29, 2017.

43. Annemans L, Lamotte M, Clarys P, van den Abeele E. Health economic evaluation of controlled and maintained physical exercise in the prevention of cardiovascular and other prosperity diseases. Eur J Cardiovasc Prev Rehabil. 2007;14(6):815-824.

44. Cradock AL, Barrett JL, Kenney EL, et al. Using cost-effectiveness analysis to prioritize policy and programmatic approaches to physical activity promotion and obesity prevention in childhood. Prev Med. 2017;95 Suppl:S17-S27.

45. Cobiac LJ, Vos T, Barendregt JJ. Cost-effectiveness of interventions to promote physical activity: a modelling study. PLoS Med. 2009; 6(7):e1000110.

46. Atsou K, Crequit P, Chouaid C, Hejblum G. Simulation-Based Estimates of the Effectiveness and Cost-Effectiveness of Pulmonary Rehabilitation in Patients with Chronic Obstructive Pulmonary Disease in France. PLoS One. 2016;11(6):e0156514.

47. Burns DK, Wilson EC, Browne P, et al. The Cost Effectiveness of Maintenance Schedules Following Pulmonary Rehabilitation in Patients with Chronic Obstructive Pulmonary Disease: An Economic Evaluation Alongside a Randomised Controlled Trial. Appl Health Econ Health Policy. 2016;14(1):105-115. 
48. Zwerink M, Effing T, Kerstjens HA, et al. Cost-Effectiveness of a Community-Based Exercise Programme in COPD Self-Management. COPD. 2016;13(2):214-223.

49. Gillespie P, O'Shea E, Casey D, et al. The cost-effectiveness of a structured education pulmonary rehabilitation programme for chronic obstructive pulmonary disease in primary care: the PRINCE cluster randomised trial. BMJ Open. 2013;3(11):e003479.

50. Hailey D, Jacobs P, Stickland M, Chuck A, Marciniuk D, Mayer I. Pulmonary Rehabilitation for Chronic Obstructive Pulmonary Disease: Clinical, Economic, and Budget Impact Analysis [Technology report number 126]. Ottawa: Canadian Agency for Drugs and Technologies in Health; 2010. Report No.: 126. Available from: https://www.cadth. ca/media/pdf/H0482_COPD_tr_e.pdf. Accessed October 10, 2018.
51. Coultas DB, Jackson BE, Russo R, et al. Home-based Physical Activity Coaching, Physical Activity, and Health Care Utilization in Chronic Obstructive Pulmonary Disease. Chronic Obstructive Pulmonary Disease Self-Management Activation Research Trial Secondary Outcomes. Ann Am Thorac Soc. 2018;15(4):470-478.

International Journal of COPD

\section{Publish your work in this journal}

The International Journal of COPD is an international, peer-reviewed journal of therapeutics and pharmacology focusing on concise rapid reporting of clinical studies and reviews in COPD. Special focus is given to the pathophysiological processes underlying the disease, intervention programs, patient focused education, and self management protocols.

\section{Dovepress}

This journal is indexed on PubMed Central, MedLine and CAS. The manuscript management system is completely online and includes a very quick and fair peer-review system, which is all easy to use. Visit $\mathrm{http}: / / \mathrm{www}$.dovepress.com/testimonials.php to read real quotes from published authors.

Submit your manuscript here: http://www.dovepress.com/international-journal-of-chronic-obstructive-pulmonary-disease-journal 